Int. J. Electrochem. Sci., 12 (2017) $2003-2012$

\title{
Electrochemical Determination of Apigenin as An Anti-Gastric Cancer Drug in Lobelia chinensis Using Modified Screen- Printed Electrode
}

\author{
Yanchun Wang ${ }^{1,2}$, Zheng Wei ${ }^{3}$, Junping Zhang ${ }^{3}$, Xuemei Wang ${ }^{1,2, *}$ and Xiao $\mathrm{Li}^{1,2, *}$ \\ ${ }^{1}$ People's Hospital of Zhengzhou University, Zhengzhou, 450003, Henan, P. R. China \\ ${ }^{2}$ Henan Provincial People's Hospital, Zhengzhou, 450003, Henan, P. R. China \\ ${ }^{3}$ Henan Academy institute of Traditional Chinese Medicine, Zhengzhou, 450000, Henan, P. R. China \\ *E-mail: wangxuemei211@ sohu.com; lesslazy_1x@163.com
}

doi: $10.20964 / 2017.03 .01$

Received: 9 November 2016 / Accepted: 22 December 2016 / Published: 12 February 2017

\begin{abstract}
We exploited a simple electrochemical method to activates bare screen printed carbon electrode and a novel amperometric apigenin sensor with high sensitivity was developed. Nickel nanoparticles (NiNPs) were doped on the activated screen printed carbon electrode (ACE), and then employed to investigate electrochemical behavior of apigenin in a $0.1 \mathrm{M}$ B-R buffer solutions $(50 \%$ ethanol, $\mathrm{pH}=3.0)$ by cyclic voltammetry $(\mathrm{CV})$. Result shows a linear relationship of peak currents as a function of apigenin concentration in the range from 0.9 to $200 \mu \mathrm{M}$. Using proposed method, the apigenin in a herbal drug (Lobelia chinensis) can be easily determined in the absence of pre-separation. This simple and convenient method is of great potential application prospect for anti-gastric cancer drug analysis.
\end{abstract}

Keywords: Lobelia chinensis; Screen-printed electrode; Sensor; Ni nanoparticles; Anti-gastric cancer

\section{$\underline{\text { FULL TEXT }}$}

(C) 2017 The Authors. Published by ESG (www.electrochemsci.org). This article is an open access article distributed under the terms and conditions of the Creative Commons Attribution license (http://creativecommons.org/licenses/by/4.0/). 